\title{
A voz e o corpo: hibridação na narrativa de Orlando Mendes, Mia Couto e Paulina Chiziane ${ }^{1}$
}

\author{
ANA TeIXEIRA \\ Centro de Estudos Africanos - ISCTE, Lisboa
}

RESUMO: A COMPLEXIDADE DOS CONTEXTOS PÓS-COLONIAIS EXIGE DA CRÍTICA A BUSCA DE DEFINIÇÕES CONCEITUAIS COM BASE EM LÓGICAS INTERPRETATIVAS COERENTES, QUE LEVEM A ESCOLHAS TERMINOLÓGICAS ADEQUADAS, POR EXEMPLO, PARA A ABORDAGEM DE QUESTÕES CONCERNENTES AOS FENÔMENOS E PROCESSOS DE CHOQUE OU FUSÃO IDENTITÁRIA. PARTINDO DA ESPECIFICAÇÃO DOS CONCEITOS DE "HIBRIDAÇÃO", "HIBRIDISMO" E "MESTIÇAGEM", O TEXTO DISCORRERÁ SOBRE AS NARRATIVAS MOÇAMBICANAS DE ORLANDO MENDES, MIA COUTO E PAULINA CHIZIANE, CONSIDERANDO QUE AS MESMAS ESPELHAM UM CENÁRIO PRIVILEGIADO DE PROCESSOS DE HIBRIDAÇÃO.

ABSTRACT: THE COMPLEXITY OF POSTCOLONIAL CONTEXTS REQUIRES FROM CRITICISM CONCEPTUAL DEFINITIONS BASED ON CONSISTENT LOGICAL INTERPRETATION THAT LEAD TO APPROPRIATE TERMINOLOGICAL CHOICES, FOR EXAMPLE, IN ORDER TO ADDRESS ISSUES CONCERNING PHENOMENA AND PROCESSES OF SHOCK OR MERGER OF IDENTITIES. STARTING FROM THE SPECIFICATION OF THE CONCEPTS OF "HYBRIDIZATION", "HYBRIDITY" AND "MISCEGENATION", THE TEXT WILL DISCUSS ON THE MOZAMBICAN NARRATIVES BY ORLANDO MENDES, MIA COUTO AND PAULINA CHIZIANE, BY CONSIDERING THEY REFLECT A PRIVILEGED SETTING OF HYBRIDIZATION PROCESSES.

PALAVRAS-CHAVE: PÓS-COLONIALISMO, HIBRIDAÇÃO, NARRATIVA MOÇAMBICANA, ORLANDO MENDES, MIA COUTO E PAULINA CHIZIANE.

KEYWORDS: POSTCOLONIALISM, HYBRIDIZATION, MOZAMBICAN NARRATIVE, ORLANDO MENDES, MIA COUTO E PAULINA CHIZIANE.

1 Este texto é um desenvolvimento da comunicação com o mesmo título, apresentada no I Congresso Internacional "Indícios. A Hibridação nas Literaturas do Oceano Índico", Universidade Autónoma de Barcelona, 23-25 de Abril de 2009. 
uem não sabe de onde vem, não sabe onde está nem para onde vai.

\section{Lilia Momplé2}

No dicionário Métissages de Arcimboldo a Zombi (2001), Francois Laplantine e Alexis Nouss excluem os termos "híbrido" e "hibridez/hibridismo" para designar processos de redefinição identitária, sustentados em encontros de culturas distintas. Contrastivamente, o termo "mestiçagem" é lido como sendo o mais adequado na sua capacidade de veicular o resultado de um processo de fusão de diferentes modos de estar na cultura e na sociedade.

A abordagem conceptual a fenómenos e processos de choque ou fusão identitária é estimulada por problematizações constantes da adequação de escolhas terminológicas. A complexidade dos contextos pós-coloniais, ao longo do processo histórico, torna inescapável a necessidade de definirmos escolhas com base em lógicas interpretativas coerentes. Na nossa leitura, importa, assim, clarificar que o conceito de "hibridação" será entendido como o processo de encontro de identidades diferenciadas. "Hibridismo" designará o resultado sociocultural desse mesmo processo. "Mestiçagem", por seu lado, referir-seá à manifestação corpórea de fusões idiossincráticas distintas. O processo de hibridação produz, deste modo, identidades híbridas (conjugações sincréticas de diferentes vivências culturais), que poderão, ou não, resultar na emergência de identidades mestiças. "Mestiçagem", ou encontro inter-racial, remete-nos a uma evidência física que se enquadra em diversos graus de perceptibilidade.

A nossa leitura considerará que das "zonas de contacto" (PRATT, 1992) inerentes ao processo colonial não resulta em uma anulação de sistemas idiossincráticos distintos, mas sim uma convivência entre ambos, gerando novas mundividências discursivas. Desta forma, observamos uma coexistência de lógicas culturais que não escapam a processos de negociação de poder, mas que não resultam necessariamente na emergência de espaços de conflito. Entendemos, assim, a hibridação enquanto um processo mutável, sujeito a constantes redefinições de fronteiras, que acabam por problematizar relações de poder e, consequentemente, possíveis definições de identidade/alteridade.

2 A aparente insolubilidade deste conflito resultante de uma procura de adaptação de conceitos concebidos abstractamente a realidade sociais, económicas e culturais concretas, ao longo dos percursos de definição de uma identidade afro-americana, é desenvolvida por Cornel West (1993), tendo como ponto de partida a teorização de Cruse. 
Cenário privilegiado de processos de hibridação, a narrativa moçambicana espelha a complexa realidade multicultural, multirracial e plurilinguística que caracteriza Moçambique. Teremos em conta dois processos distintos, mas coexistentes: a hibridação cultural e a hibridação racial. Deste modo, "voz" e "corpo" metaforizam a ocorrência de encontros inter-raciais e interculturais, contribuindo ambos para a definição de uma identidade terceira. A aceitação ou a negação dessas novas realidades identitárias no espaço ficcional dialoga, em nosso entender, com os contextos sociais e políticos onde as mesmas se inserem.

A leitura do texto enquanto corpo e o entendimento do corpo enquanto texto coexiste com a constatação de perfis idiossincráticos que ultrapassam a tangibilidade corpórea. Observaremos esse complexo processo de formação identitária em três textos: Portagem, de Orlando Mendes, cuja primeira edição data de 1965; O Outro Pé da Sereia (2006), de Mia Couto; e O Alegre Canto da Perdiz (2008), de Paulina Chiziane.

A nossa abordagem encontrará como suportes de leitura os conceitos bakhtinianos de "dialogismo", "heteroglossia" e "cronótopos", bem como a problematização do conceito de "terceiro espaço”, desenvolvido por Homi Bhabha. Nesse sentido, consideraremos a pluralidade de linguagens que compõem os espaços textual e paratextual, encerrando uma constante intencionalidade enunciatória, contextualmente balizada.

Consideraremos os dois processos interactivos na construção de identidades híbridas, que mencionámos - a hibridação cultural ("voz") e a hibridação racial ("corpo") - pressupondo a sua inter-relação com contextos históricos particulares: o contexto colonial "intra" e "extranarrativo" de Orlando Mendes influi na construção de um conceito particular de "mestiçagem", com implicações socioculturais próprias; o diálogo entre colonialismo e pós-colonialismo em Mia Couto e em Paulina Chiziane, espelha a implicação do processo histórico no entendimento do "eu" individual e de um "eu" colectivo. Assim, pretendemos demonstrar a evidência presente nas três narrativas de que:

1. existe uma interacção entre as duas manifestações centrais do processo de hibridação: hibridismo cultural e mestiçagem;

2. o processo de hibridação condiciona a construção de identidade/s, designadamente, através da conjugação dos conceitos socioculturalmente construídos de "raça", "classe" e "género"; 
3. a construção identitária resulta de um processo dialéctico entre espaços e tempos específicos.

\section{Processos de hibridação em Orlando Mendes, Mia Couto e Paulina Chiziane}

Definindo o conceito teórico de "cronótopos", Mikhail Bakhtin afirma: 'We will give the name chronotope (literally, 'time space') to the intrinsic connections of temporal and spatial relationships that are artistically expressed in literature. (..) It expresses the inseparability of space and time (time as the fourth dimension of space)". (BAKHTINE, 2001, p.15). A inter-relação espaço-tempo de que nos fala Bakhtine, é determinante nos textos de Orlando Mendes, Mia Couto e Paulina Chiziane, que nos propomos analisar. Esse mesmo encontro conceptual está subjacente a processos de hibridação cultural e racial, que resultam na sua essência de diálogos entre realidades históricas, cronologicamente sequenciadas. O resultado da presença colonial portuguesa, historicamente demarcada, encontra expressão diegética, consolidando, directa ou indirectamente, uma lógica cronotópica. A determinação espacial, no seu diálogo com o tempo histórico, atribui um papel significativo ao conceito de viagem, que deverá ser entendido objectiva e simbolicamente: a deslocação física das personagens coexiste com percursos subjectivos pelos espaços da memória.

O romance Portagem foi inicialmente publicado em 1965, em plena guerra colonial. Construindo o percurso de João Xilim, Mendes dá forma a um complexo conflito identitário, no qual a triangulação raça/género/classe se torna determinante. Das origens históricas desse jogo de hibridação presente na narrativa de Orlando Mendes, nos fala O Outro Pé da Sereia, de Mia Couto. Publicado em 2006, o romance de Mia Couto intercala relatos da viagem da nau Nossa Senhora da Ajuda, de Goa para Moçambique, entre 1560 e 1561. Paralelamente ao percurso físico do "provincial dos jesuítas na Índia Portuguesa" (COUTO, 2006, p. 61), D. Gonçalo da Silveira e do Padre Manuel Antunes, a narrativa acompanha também o mês de Dezembro de 2002, em Moçambique, mês que conduz Mwadia Malunga num regresso ao espaço da sua infância, no qual o tecer de múltiplas vozes na busca do entendimento 
identitário revela uma continuidade subtil entre as duas realidades espaciotemporais da diegese. Também em O Alegre Canto da Perdiz, a deslocação no espaço acompanha o encontro entre a presença colonial portuguesa e o fim da guerra civil, em 1992. Sem referência a datas, a realidade histórica é, em Chiziane, veiculada pelos caminhos das personagens, que literal e simbolicamente representam uma busca identitária, assente num complexo confronto de construções conceptuais de raça, género e classe.

Parece-nos, então, legítimo o pressuposto de que as três narrativas se estruturam a partir do já referenciado triângulo conceptual raça/género/classe, sempre construído social e culturalmente. Num diálogo entre Laura, patroa recente do muleque Xilim, e a sua filha Maria Helena, a determinação da mestiçagem no percurso do protagonista é, desde logo, anunciada. Para D. Laura, os mulatos: "São mais falsos do que os pretos", ao que Maria Helena responde "os muleques pretos são tão estúpidos, mãe". (MENDES, 1991, p.17). Filho do encontro entre a sua mãe, Kati, e o branco Patrão Campos, momento que retorna constantemente na narrativa e que é amaldiçoado por ele próprio, Xilim pergunta significativamente à sua mãe: "Porque eu não sou preto como toda a gente?". Kati responde: "Tu nasceu mais claro porque nasceu numa noite de lua grande. Mas tu és negro como tua mãe e teu pai”. O diálogo entre as duas personagens, e a discriminação que Xilim sofre ao longo do seu percurso na narrativa de Mendes, remetem-nos para a discussão do próprio conceito de africanidade. Há que entender que não é concretamente a evidência corpórea da raça que se torna determinante no entendimento e na aceitação identitária, mas sim a determinação sociocultural a ela subjacente. Dando voz ao protagonista, o narrador afirma: “...Mal de mim é ser mulato. ... Branco está sempre a pensar que mulato é filho dum crime...” (MENDES, 1991, p. 53).

A valorização da cor da pele enquanto evidência necessária da identidade africana é particularmente defendida e contestada na construção de duas personagens determinantes para o entendimento do diálogo corpo/ voz, em O Outro Pé da Sereia. Viajando de Nova Iorque para Vila Longe, nas palavras do empresário Casuarino uma "comunidade autêntica e autenticada" (COUTO, 2006, p.176), o historiador afro-americano Benjamin Southman procura reencontrar raízes identitárias, guiado por uma lógica pan-africanista. Entrevistado por Southman para esse propósito que conjuga o interesse profissional do historiador à busca individual do autoconhecimento, o barbeiro Ar- 
canjo Mistura, ex-revolucionário da FRELIMO, desconstrói a argumentária de Southman, desvalorizando a defesa da afirmação dos africanos, enquanto causa comum no continente e na diáspora. Ao considerar Janet, a americana branca, viúva de Eduardo Mondlane, como sendo uma verdadeira afro-americana, Arcanjo Mistura atribui um novo sentido ao conceito de africanidade, cujo entendimento é inviável em contexto afro-americano. Neste momento narrativo, a plasticidade identitária que resulta da construção conceptual de raça, torna-se particularmente evidente.

O debate suscitado pela problematização da identidade africana opôs duas correntes de pensamento referenciais, na primeira metade do século XX: o essencialismo do movimento da Négritude e a defesa da individualidade identitária que a ideia de nação suscita. Nesta dualidade teórica, as reflexões dos franco-africanos Leopold Senghor (Senegal) e Aimé Cesaire (Martinica), defensores de uma essência africana combinando raça e cultura além das fronteiras nacionais, opõe-se à posição nacionalista defendida por Frantz Fanon. A dualidade "nação" / "essência identitária global" é resumidamente referida por Ania Loomba, que citamos:

For Fanon, native intellectuals who take to 'the unconditional affirmation of African culture' are mistaken since such a category simply inverts colonial stereotyping. For Cesaire, on the other hand, it is the nation that is 'a bourgeois phenomenon' ... and true radicalism demands forging solidarities across its boundaries. (LOOMBA, 2005, p. 178).

No cerne desta dualidade está a construção conceptual de classe, frequentemente associada ao conceito de raça e ao posicionamento social e histórico da identidade africana. Do debate entre os teóricos que mencionamos surge a inevitabilidade de problematizar o papel do intelectual africano que, ao longo do percurso de afirmação identitária, tem emergido como porta-voz de idiossincrasias respeitantes a diferentes sectores socioeconómicos. Esse elitismo discursivo, que não raro acompanha a problematização e o questionamento de papéis de liderança no Ocidente, foi contraposto designadamente por António Gramsci (1929-30), cujo conceito de "intelectual orgânico" propõe na sua essência uma inter-relação entre o discurso teórico e a tomada de consciência de uma estratificação social e económica. Essa mesma leitura será directamente 
apropriada pelo teórico brasileiro Paulo Freire (1970), na sua reconceptualização do processo educativo. Sendo a questão da liderança político-ideológica, em diálogo com o amadurecimento de uma intelectualidade afro-americana, dominante durante a década de sessenta do século XX, Harold Cruse (1967) discute a correlação dos conceitos de raça e classe, desenvolvendo a complexidade inerente ao conceito de líder no seio da comunidade afro-americana ${ }^{3}$.

Em O Outro Pé da Sereia, Benjamin Southman veicula o contraponto entre o distanciamento inerente à abordagem científica do historiador/etnólogo, e a subjectividade associável à sua própria busca de definição identitária. Indissociável desta negociação entre o papel de sujeito e o papel de objecto, o conceito de "classe" enquanto factor de cisão social correlaciona-se directa ou indirectamente com o processo de hibridação racial.

Em Portagem, o poder sociocultural da família Campos, brancos que simbolizam a presença colonial portuguesa, adquire forma na função de muleque que João Xilim ocupa na casa. No início da narrativa tem lugar um interessante jogo de poder entre a cozinheira Rosa e o recém - chegado Xilim, a quem a mulher comenta: “...João ... ainda vá lá... Agora Xilim é que me parece muito para começar.” (MENDES, 1991, p.16). Este confronto sugestionado por Rosa e submissamente aceite por Xilim, canaliza a justaposição raça/ classe de uma forma subtil, mas efectiva. Adoptando uma estratégia narrativa analéptica, o narrador explica a origem do nome Xilim, evocando o regresso de um parente de João, vindo das minas do Kaniamato, que lhe dera uma "moeda reluzente" (MENDES, 1991, p.16). O protagonista exclamara "Tenho xilim, tenho xilim", justificando-se, assim, a sua alcunha. Não será desprovida de intencionalidade político-ideológica a referência à cor da pele da cozinheira Rosa, bem como o desenvolvimento de uma hierarquia entre a própria subalternidade doméstica existente na casa do Patrão Campos. A dicotomização sugestionada pelo comentário de Rosa veicula um paralelismo

3 Em 10 de Novembro de 1963, o activista afro-americano Malcom X profere o discurso "Message to the Grassroots", em Detroit, estado do Michigan. Desenvolvendo a temática da hierarquização social entre a comunidade de escravos, Malcom X estabelece uma clara distinção entre os que apelida de "house negros" e "field negros", assente na sua essência no contraste entre uma postura de submissão e uma predisposição para a revolta. Não obstante as inegáveis diferenças entre o contexto norteamericano e a realidade moçambicana, no que respeita ao desenvolvimento histórico, social, cultural e económico do conceito "raça", o paralelismo que aqui estabelecemos sustenta-se no argumento de que a concretização de hierarquias de classe tem lugar também intra-racialmente. 
intertextual entre a realidade afro-moçambicana em época colonial e a inegável concretização de jogos de poder no seio da comunidade de escravos afro-americanos durante o período esclavagista ${ }^{4}$.

Essa mesma hierarquização de classe que se desenvolve no seio da população africana colonizada e explorada - o que podemos considerar como um interessante desdobramento das relações de poder inerentes à construção do binário eu/o outro, resultantes do próprio processo colonial - encontra expressão em O Outro Pé da Sereia no desenvolvimento da personagem Nimi Nsundi, um escravo que acompanha a missão do navio Nossa Senhora da Ajuda. O posicionamento da personagem oscila entre a condição de subalternidade que a realidade objectiva fixa através de evidências corpóreas - "Ele não era tocável, era um escravo, um ser da outra margem” (COUTO, 2006, p.62), e um questionamento da objectividade identitária, consolidado na referência às suas origens. Estas espelham o subjectivo resultado da plasticidade identitária que caracteriza o diálogo entre as realidades colonial e pós-colonial:

O orgulho vinha de longe: o ajudante de meirinho não era um simples cafre. Tinha sido capturado no Reino do Congo e enviado para Lisboa em troca de mercadorias que o Rei Afonso I, aliás Mbemba Nzinga, mandara vir de Portugal. Nsundi era um "trocado", uma moeda de carne. O homem custara uma espingarda, cem espoletas, cinquenta balas de chumbo, um barril de pólvora e uma pipa de cachaça. (COUTO, 2006, p. 63).

A exceptionalidade de Nsundi, que o progresso da narrativa revelará continuada, anuncia-se, desde logo, no papel que desempenha no navio: "Era um escravo particular: em terra, cumpria funções de mainato; no mar, era um estrinqueiro, encarregado de zelar pelas velas e pelos cabos. Cumpria essa função desde há cinco anos. Nesta viagem ele fora promovido: auxiliava o meirinho" (COUTO, 2006, p. 63).

4 A lei da assimilação entrou em vigor em 1919 em Moçambique, implicando a rejeição de hábitos culturais autóctones em prol de uma vivência artificialmente europeizada. A atribuição do "certificado de assimilação" dependia, designadamente, da prática da monogamia, concedendo o acesso a privilégios correntemente negados à população afro-moçambicana: possibilidade de registo de filhos, acesso ao regime jurídico colonial, isenção de trabalho forcado, entre outros. A medida foi alvo de critica por parte de uma nova elite intelectual afro-moçambicana então emergente, e particularmente expressa por João Albasini em artigos publicados no Brado Africano (ISAACMAN, 1988). 
Em contexto pós-colonial, o momento narrativo que representa o presente diegético, Mia Couto concentra no empresário Casuarino Malunga o significado da ascensão socioeconómica que recria uma nova hierarquização de classe, numa realidade recorrentemente apelidada de neocolonial. O escritor queniano Ngugi wa Thiong'o observa uma transição da lógica imperialista colonial para uma lógica imperialista neocolonial, a partir da década de 70, afirmando:

...The decade saw the clear ascendancy of US-engineered transnational financial and industrial monopolies in most of Ásia, África and Latin América. This ascendancy was to be symbolised by the dominance of the IFM and the World Bank in the determination of the economies and hence the politics and culture of the affected countries in Asia, Africa and Latin America. ... (WA THIONG'O, 1993, p. 68).

A construção da personagem Casuarino sugere um segundo nível de afirmação da lógica neocolonial, com uma irónica inversão de papéis: o casal Southman torna-se objecto de exploração. Ao receber os afro-americanos com "honras de estado", Casuarino, aceitando o dinheiro dos visitantes, diznos o narrador:

... foi conferindo os dólares, somando os valores as quantias. Deteve-se mais tempo do que seria seguro. Mas ele deleitava-se em manusear notas que permaneciam lisas, intactas e cheirosas. O empresário não pôde deixar de comparar o estado daquelas notas com o dos meticais que circulavam sujos, rasgados e amassados (COUTO, 2006, p. 163).

Em O Alegre Canto da Perdirg, a centralidade da ascensão social afirma-se como espelho da cedência a idiossincrasias opressoras. José dos Montes luta e conquista a condição de assimilado, no sentido de responder à ambição de Delfina. A imagem de anulação identitária que o estatuto de assimilado representa é veiculada pela imagética que habita o discurso do narrador:

Quem não se ajoelha perante o poder do império não poderá ascender ao estatuto de cidadão. Se não conhece as palavras da nova fala jamais se poderá afirmar. Vamos, jura por tudo que não dirás mais uma palavra nessa língua 
barbara. Jura, renuncia, mata tudo, para nasceres outra vez. Mata a tua língua, a tua tribo, a tua crença. Vamos, queima os teus amuletos, os velhos altares e os velhos espíritos pagãos. José faz o juramento perante um oficial de justiça, que mais se parece com um juramento de bandeira ... (CHIZIANE, 2008, p. 117)

A língua enquanto elemento central para o entendimento e para a negociação identitária em contexto colonial expressa a ocorrência de um processo de hibridação, prioritariamente assente no anular da diferença. O domínio da língua portuguesa é n'O Alegre Canto da Perdiz um veículo de ascensão económica, através de um processo interno à lógica colonial, e n’O Outro Pé da Sereia, um instrumento de poder e de protagonismo, em contexto de submissão. Dia Kumari, aia goesa de D. Filipa, tripulante do Nossa Senhora da Ajuda, e o escravo Nimi Nsundi, falam português. Dia reconhece na sua língua, o concanin, um poderoso elemento de afirmação cultural, em perfeito contraste com Jesustino, padrasto de Mwadia, um indiano sem Índia no Moçambique de 2002, que escolhe tornar voluntário o esquecimento de raízes involuntariamente anuladas. Num diálogo com o seu ajudante, Singério, o alfaiate Jesustino torna clara a sua posição:

Singério dava-lhe as boas vindas, nas únicas palavras de gujurate que aprendera de seu velho mestre. Jesustino tinha o ar sério, quase desolado, quando pediu:

- Nunca mais fale isso para mim, Singério!

- ... É língua da Índia, língua de seus avós.

- Não quero que me fale nessa língua! (COUTO, 2006, p. 327)

Jesustino evoca um sentimento de distanciamento face ao seu pai, Agnelo, aquando da utilização de gujurate, que em criança não entendia. Essa recordação transmite um progressivo processo de desconexão com raízes identitárias, que se acentua intergeracionalmente.

O retrato da hibridação racial no seio da comunidade indiana em Moçambique representa a multiplicidade étnicocultural que compõe o país: em Portagem, o "monhé" Ibrahimo, cuja loja é ponto de encontro de sentenciados; em O Outro Pé da Sereia, os “canecos" (COUTO, 2006, p. 158) Jesustino Rodrigues e Luzmina, asiáticos, portugueses, africanos, sem uma lógica identitária conciliatória, que Luzmina parece buscar na fé católica. No navio Nossa Se- 
nhora da Ajuda, a aia Dia, metáfora de terras de Goa, o goês Fernandes, físico de bordo. Em O Alegre Canto, os filhos de Lavaroupa da Silveira.

$\mathrm{Na}$ narrativa de Chiziane, a triangulação raça/classe/género informa determinantemente o contexto narrativo, num percurso que se afirma também intergeracional. Mãe e filha, Serafina e Delfina revelam posicionamentos contraditórios relativamente ao significado da cor da pele, que remetem para a sua própria indefinição de um sentido de ser e de estar. Serafina opõe-se ao casamento de Delfina com José dos Montes, e Delfina, cedendo inicialmente ao impulso da paixão, passará gradualmente a um posicionamento calculista e materialista. A sua exigência de um nível de vida inacessível à população afromoçambicana conduz José dos Montes à rendição perante a estrutura colonial. Delfina reafirma o determinismo da estratificação socioeconómica, sustentada pela cor da pele, que ironicamente se torna ela própria num veículo para a sua própria ascensão económica. É, de facto, a cor da sua pele que, como resultado da exotização do corpo feminino africano ${ }^{5}$, a torna objecto de desejo do branco Soares e dos homens que tornam rentável a venda do seu corpo. Dando forma à "coisificação" do corpo feminino, Delfina entende-o enquanto fonte de lucro e valoriza-o na sua capacidade de produzir descendência branca. Os filhos mulatos, fruto da sua relação com Soares, Maria Jacinta e Luizinho, alvos de um tratamento diferenciado, evidenciam a objectivação do corpo feminino enquanto veículo de um pretenso processo de purificação da raça, que é referido e exaltado por Serafina, ao opor-se ao casamento da sua filha com José dos Montes. Maria das Dores, filha de José dos Montes, é vendida pela sua mãe, Delfina, ao velho curandeiro Simba, o que uma vez mais, nos remete para uma concepção do corpo feminino enquanto objecto produtivo e reprodutivo.

A inter-relação género/raça assume contornos distintos em Portagem e O Alegre Canto da Perdiz. O posicionamento social de Maria Jacinta, filha

5 Em contexto afro-americano, a objectivação do corpo da mulher concretiza-se na emergência de estereótipos assentes na associação de traços de personalidade, características corporais e estatuto socioeconómico. Considerando a classificação da feminista afro-americana Patrícia Hill Collins, torna-se viável um paralelo entre a construção do tipo Jezebel e a coisificação do corpo feminino, que Chiziane constrói. Citamos Collins: “...Jezebel, whore, or sexually aggressive woman - is central in this nexus of elite white male images of Black womanhood because efforts to control Black women's sexuality lie at the heart of Black women's oppression. (...) Jezebel's function was to relegate all Black women to the category of sexually aggressive women, thus providing a powerful rational for the widespread sexual assaults by white men (...)" (COLLINS, 1991, p. 77) 
mulata de Delfina, contrasta em absoluto com a situação do mulato João Xilim. Em Portagem, importa, ainda, observar que a diferença de género não conduz à distinção de representatividade social, cultural e económica, com base na raça. Luísa, mulher de Xilim, que o trai com o cantineiro branco, Esteves, merece do protagonista o seguinte comentário: “- Mulata é assim mesmo: olhar de branco, levanta as saias; palavra bonita de branco com uma prenda na mão, abre as pernas" (MENDES, 1991, p.134). A mulher branca, ou quase branca (como Maria Jacinta em O Alegre Canto da Perdiv), adquire um protagonismo diferenciado nas três narrativas. Em Portagem, Maria Helena, filha do Patrão Campos, relacionando-se com João Xilim, num acto para ela inconscientemente incestuoso, inverte o processo de objectivação do corpo, sendo ela o sujeito, e Xilim o objecto. Encontramos neste momento um exemplo da hierarquização racial, que se evidencia também em $O$ Alegre Canto da Perdir, no qual a mulher branca de Soares acaba por reconquistar o marido, que abandona Delfina, regressando à casa.

Nas três narrativas em análise, a maternidade ocupa um lugar ambíguo entre a afirmação do protagonismo específico da mulher, e a veiculação da sua própria cedência ao sistema colonial. A concepção do corpo feminino enquanto objecto produtivo e reprodutivo invalida o posicionamento de Júlia Kristeva (1977), que encara a maternidade como capacidade feminina de abalar o império "falogocêntrico", num diálogo teórico com o conceito derridaniano de "logocentrismo". Pelo contrário, é justamente esse domínio do masculino sobre o feminino, não anulado pela maternidade, que produz uma ambiguidade identitária, que alimenta e se alimenta de lógicas socioeconómicas totalitárias. Os filhos dos corpos mestiços de Luísa e João Xilim ocupam a realidade simbólica de um terceiro espaço identitário (BHABHA, 1994), que torna tangível o processo de hibridação racial.

A estrutura diegética intergeracional de O Outro Pé da Sereia conduz à reaproximação de Mwadia e da sua mãe, Dona Constança, como resultado do reencontro da filha com o espaço das suas raízes. Chegando o dia da partida para Vila Longe, Mwadia visita o adivinho Lázaro, cujas capacidades de conhecer para além da evidência física presente, contrastam com a utilização do telemóvel, dando forma a um encontro entre tradição e modernidade ou, pelo contrário, contribuindo para a anulação dessa dualidade civilizacional. O diálogo entre Mwadia e Lázaro indicia desde logo a ocorrência de um pro- 
cesso de hibridação cultural, advindo de mundividências espirituais distintas, que, no entanto, convivem sem conflito:

- Há muito que lhe queria dizer isto, Mwadia Malunga: você ficou muito tempo lá no seminário, perdeu o espírito das nossas coisas, nem parece uma africana. - Há muitas maneiras de ser africana. (COUTO, 2006, p. 55)

A convivência não conflitual de valores culturais distintos conduz, no entanto, a uma indefinição identitária, nas palavras de Mwadia. A imprecisão no que realmente significa ser "africana" remete-nos para a emergência de um limbo identitário, de um não-lugar, resultante de realidades culturalmente híbridas. A personagem dá forma a uma concepção generalizada e abrangente da identidade africana, inviabilizando a discussão do significado de ser "moçambicana/o". Couto constrói e reconstrói um novo sentido de moçambicanidade a partir do reconhecimento da presença de uma realidade identitária pan-africanista.

O encontro intercultural, que aproxima o continente americano do continente africano, é metaforizado de forma particular na personagem Rosie, mulher afro-brasileira de Benjamin Southman. Rosie é o resultado da triangulação Europa/ América/ África, evocando um tempo histórico que nos é veiculado através da intercalação de relatos de viagem do navio seiscentista Nossa Senhora da Ajuda. Significativamente aludindo às consequências socioculturais inerentes a processos de mestiçagem, Rosie afirma em conversa com o ex-pugilista Zeca Matambira, personagem que metaforiza a coexistência paradoxal entre a celebração do corpo africano masculino e a discriminação racial de que sempre foi alvo: "- Estou tão cansada de ter pele" (COUTO, 2006, p. 342).

Em O Outro Pé da Sereia, o diálogo entre tempos e espaços distintos, que se concretiza na alternância entre analepses e prolepses, estrutura a ideia de que a hibridação só acontece como resultado da viagem. Física e simbolicamente concebida, é a viagem no espaço e no tempo que possibilita a autodescoberta de Benjamin Southman, descendente do escravo Nimi Nsundi e da aia goesa Dia Kumari. É a viagem de Mwadia que permite o seu regresso a um significado autêntico do “eu”, em Vila Longe. É a viagem, afinal, que dá forma a encontros inter-raciais, resultantes de uma heterossexualidade invasiva de 
espaços e de ventres. Lembremos o conceito de "Lusotropicalismo", de Gilberto Freyre (1933), promotor de uma visão harmoniosa e assim romantizada da capacidade de criação de ambiguidades identitárias, espaços mestiços resultantes do projecto colonial português. Observemos António Caiado em $O$ Outro Pé da Sereia, marido de D. Filipa, que “...se envolvera com negrinhas várias e se desdobrara em diversas proles de mulatos." (COUTO, 2006, p. 291).

Exemplo de uma realidade racialmente policromática, o universo de Lavaroupa da Silveira, em o Alegre Canto da Perdiz, constrói um microcosmo do corpo colonizado. Valorizando a criança mestiça que Delfina deu à luz e que denuncia a sua traição matrimonial, Lavaroupa da Silveira celebra o seu próprio contexto familiar multirracial, amostra da realidade sociocultural que o contextualiza, reconhecendo os benefícios sociais e económicos de uma crescente adulteração da "raça negra" perante o sistema colonial, e acreditando no convívio harmonioso e romantizado das diferenças: "...a vida é uma reconciliação permanente. Até os paladares brancos e pretos se reconciliam na mesa posta. É o bacalhau e o chicoa. A sardinha e o pende. O cajú e a maçã. A mandioca e a batata. Sexo de preto e sexo de branco." (CHIZIANE, 2008, p.196).

O hibridismo cultural resulta nas três narrativas do encontro entre distintas vivências da espiritualidade e de culto. Em Portagem, o paradoxo do trabalho missionário, que impõe concepções próprias e dogmáticas de ética, é simbolizado pelas personagens D. Madalena e D. Jesuína, representantes da "Cruzada Feminina de Socorros Morais e Sociais", que visitam Maria Helena, declarando: “... A nós interessa-nos o seu caso porque é de uma família branca e temos obrigação de proteger moral e socialmente os da nossa raça para que possa tornar-se superior pelos seus exemplos. (...)". Maria Helena responde: "-Desculpem-me, não pensei que na vossa misericordiosa missão distinguissem raças" (MENDES, 1991, p. 93).

Em O Alegre Canto da Perdiz, o saber de curandeiros e a religiosidade católica coexistem através de Moyo (a quem José dos Montes põe fim à vida, num gesto que metaforiza o corte com as raízes africanas) e de Simba; do significado dos casamentos religiosos de Delfina e de Maria Jacinta; do Cristo Bantu em casa do padre Benedito e do médico Fernando, filhos de Maria das Dores, como nos revela o final catártico da narrativa.

Em O Outro Pé da Sereia, o projecto missionário colonial não escapa a um convívio entre diferentes vivências espirituais e irónicas inversões de essên- 
cias identitárias. A morte do escravo Nsundi é seguida de uma "missa pagã"; Manuel Antunes renuncia ao sacerdócio e converte-se à cultura africana. Em 2002, a fé na Igreja Apostólica coexiste com crenças espirituais tradicionais de Zero Madzero, marido de Mwadia; o catolicismo é fervorosamente vivido por Luzmina, tia de Mwadia, irmã de seu padrasto Jesustino Rodrigues, com quem mantivera uma relação incestuosa. A imagem que estabelece uma ponte entre os dois momentos narrativos, Nossa Senhora para os católicos, senhora das águas para os africanos (Mama Watti), num paralelismo cultural inegável com Iemanjá, metaforiza uma essência identitária universal, adaptável e experienciável em contextos históricos, sociais e culturais distintos.

\section{Considerações finais}

Terminamos a nossa leitura de processos de hibridação nas três narrativas abordadas, referindo-nos à transmutação intercultural de concepções de espiritualidade, canalizando um encontro entre o dito sagrado e profano, que traduz mais uma evidência do dualismo conceptual característico do Ocidente. A nossa leitura permite identificar essa mesma plasticidade e adaptabilidade das diversas expressões de hibridismo que, não negligenciando as diferenças, se afirmam como pontes de continuidade intertextual. É, deste modo, possível detectar uma estrutura dialógica intra e intertextual nas três narrativas. Intratextualmente, tempos e espaços interagem, mantendo uma coerência lógica, que revela e permite revelar realidades entendidas e subentendidas. Intertextualmente, o diálogo entre as três narrativas concretiza um entendimento da determinação do contexto para o entendimento do texto. $\mathrm{O}$ contexto da diegese é, no nosso entender, produto, do contexto da produção escrita, nos três romances.

O corpo textual, híbrido, multifacetado, inclusivo, dá voz a complexos encontros entre corpos sociais, culturais e raciais que só são entendidos no seio de realidades específicas, que ultrapassam o próprio texto. É precisamente essa determinação de contextos que influi numa flexibilização categorial e que constrói a plasticidade do conceito de "raça" e dos papéis de género. O terceiro espaço lê-se em corpos de vozes que o protagonizam, em textos que dão forma a esse protagonismo, em contextos que informam a sua lógica. 


\section{Referência Bibliográfica}

BAKHTIN, Mikhail. Discourse in the novel. In HOLQUIST, Michael (ed.). The dialogic imagination: four essays by M. Bakhtin. Trad. Caryl Emerson e Michael Houquist. Sustin: University of Texas Press, 1991, p. 125-237.

BHABHA, Homi. The Location of Culture. New York: Routledge, 1994.

CHIZIANE, Paulina. O Alegre Canto da Perdiz. Lisboa: Editorial Caminho, 2008.

COLLINS, Patricia. Hill Black Feminist Thought. Knowledge, Consciousness, and the Politics of Empowerment. New York: Routledge, 1991.

COUTO, Mia. O Outro Pé da Sereia. Lisboa: Editorial Caminho, 2006.

CRUSE, Harold. The Crisis of the Negro Intellectual. New York: William Morrow and Company, 1967

FORGACS, David (ed.).The Antonio Gramsci Reader: Selected Writings 1916-1935. New York: NYU Press, 2000.

FREIRE, Paulo. Pedagogy of the Oppressed. New York: Continuum, 1997.

FREYRE, Gilberto. Casa-Grande e Senzala. Rio de Janeiro e São Paulo: Editora Record, 2002.

GOLDMAN, Peter. The Death and Life of Malcom X. University of Illinois Press, 1979.

ISAACMAN, Allen (ed.). The Life History of Raul Honwana. An Inside View of Mozambique from Colonialism to Independence, 1905-1975. Boulder: Lynne Rienner, 1988.

KRISTEVA, Júlia. Motherhood according to Giovanni Bellini. In Kristeva, Desire in Language. New York: Columbia UP; Oxford: Blackwell, 1980. p. 237-270.

LAPLANTINE, Francois e Nouss, Alexis. Métissages de Arcimboldo a Zombi. Paris: Pauvert, 2001.

LOOMBA, Ania. Colonialism/Postcolonialism. London: Routledge, 2005

MENDES, Orlando. Portagem. Lisboa: Edições 70, 1991.

MOMPLÉ, Lília. Neighbours. Maputo: Associação de Escritores Moçambicanos, 1999 .

PRATT, Mary Louise. Imperial Eyes. Studies in Travel Writing and Transculturation. New York \& London: Routledge, 1992.

SALLIS, John (ed.). Deconstruction and Philosophy: The Texts of Jacques Derrida. Chicago: Chicago University Press, 1989.

WA THIONG'O, Ngugi. Moving the Center. The Struggle for Cultural Freedoms.

London: James Currey, 1993. 